\title{
Developing Critical Literacy Skills through \\ Using the Environment as Text
}

\author{
JOAN M. CHAMBERS \\ Lakehead University \\ CHRISTY L. RADBOURNE \\ Lakehead District School Board
}

\begin{abstract}
Through a project funded by the Ontario Ministry of Education called the Teacher Leadership and Learning Program (TLLP), teachers in a Grade 2 and a Grade 6 class incorporated the outdoor environment as a teaching text to develop critical literacy skills of their students. The findings of our interviews with them showed improvement in literacy abilities, particularly for Indigenous learners. In addition to improving their literacy skills, the children in the study also developed respect and caring for their place, the environment, and for one another. Framed by ecosocial theory, this research demonstrated the children's abilities to utilize critical literacy skills to 'read their world' and take action.
\end{abstract}

Ontario's Ministry of Education focusses on improving critical literacy skills, primarily as demonstrated on the Grades 3, 6 and 10 Education Quality and Accountability Office (EQAO) tests, through an intensive strategy designed to improve literacy pedagogy and create a standardization of practices across the province (Fullan, 2013). The overall goal is to raise the 'pass' rate to seventy-five percent across the province. Significant related goals include improving outcomes for Indigenous students, who continue to experience a significant gap in achievement as compared to their nonIndigenous peers (Hare, 2012; Luke \& Freebody, 1997; Richards, Hove, \& Afolabi, 2008). Despite gains in the overall 'pass' rate, the provincial average has yet to reach the benchmark, and there has not been a significant improvement in Indigenous student achievement.

The Ontario Ministry of Education funds Teacher Leadership and Learning Program (TLLP) projects, specifically concerning literacy and numeracy best practices (see http://www.edu.gov.on.ca/eng/teacher/tllp.html for more information). The authors obtained funding from the Ministry for a TLLP project designed to explore the teaching of foundational critical literacy skills, utilising the natural environment as the teaching text. In other words, the natural environment was conceptualized as a 'text', which furthered the children's environmental literacy, connections, sense of place, and attitudes. For example, a primary class practiced inferring from the natural environment, plant growth and attendent fauna species, the seasons, daily weather, or movement of animals. 
The project was conducted with Grade $2^{1}$ and Grade 6 students to integrate literacy, mathematics, and science with the environment as the integrating context for all three subjects. For instance, a local plant species garden and outdoor learning space were created for reflective and creative thought and for the integration of aspects of soils, plants and biodiversity, including Indigenous traditional uses of local plants as taught by an Indigenous Elder. Other partnerships engaged within the community included the Lakehead Regional Conservation Authority, the local school board's outdoor centre, and The Centre for Place and Sustainability Studies located at Lakehead University.

The purpose of this paper is to share our findings from the TLLP project, with a particular focus on the changes and literacy gains made by Indigenous learners. We explain the theoretical framework and literature we drew on for this study, describe the methodology, discuss the findings, and offer suggestions for future research.

\section{Theoretical Framework}

This study was grounded in ecosocial theory, which considers social theory in light of ecological perspectives. As human beings, we are not separate from the natural world but are interconnected with it. Consequently, an ecosocial theory helps to answer questions around how our place, identity, dispositions and discourses shape and are shaped by the social as well as the physical or material world. Ecological perspectives as well as human/social perspectives inform an ecosocial theory.

Merleau-Ponty sought to bridge the divide between language, social action and the physical, non-verbal world (Davis, 2004). Davis stated, "Merleau-Ponty suggested...that human interpretive systems, including language, are rooted in and conditioned by our primal engagements in the world. ...[He] advocated attentiveness to both the cultural and the biological" (pp. 146-7). Along similar lines, Lemke (1995) suggested that human social actions (as the basis of human social systems) have "both a material, ecological aspect and a cultural, semiotic one....[That] underlying them are the interconnected doings, the ecological and social processes that link organism to organism, and organisms to environments" (pp. 93-4). Merleau-Ponty's and Lemke's notions of the interconnectedness of the cultural/social and biological/ecological forms the basis for the construction of an ecosocial theory - a theory that recognises ecological perspectives and the complexity of human systems operating within the larger world.

Lemke (1995) proposed that "an ecosocial system is a human social community taken together with the material ecosystem that enables, supports and constrains it. ... An ecosocial system is simultaneously a material and social semiotic system" (p. 119). In this way, human semiotic resource systems and processes, such as discourse and language, can be seen as relational to and part of material or physical semiotic resource systems and processes. These are not separate processes and systems, though they are usually treated as such. And it is by not viewing the social alongside the material that humans have lost that sense of connection and awareness of how the physical world, including the environment, shapes and is shaped by human cultural practices and processes. This suggests that it is entirely conceivable to perceive the environment $a s$ text

\footnotetext{
1 The project's original plan was to carry out the study with Grade 3 and Grade 6 teachers and their students, particularly in light of EQAO testing at the Grade 3 and 6 levels, but in the fall reorganization of classrooms, the Grade 3 teacher was moved to Grade 2. It was decided to continue the project with the Grade 2 teacher as she had previously agreed to be involved and was still keenly interested in doing so.
} 
as proposed by Stables (1996) and Stables and Bishop (2001). An ecosocial theory helps to explain how discourse and texts (literary and environmental) are shaped by human interaction with the social and physical world, and in turn, dialogically shape human perspectives of and relationship with that world. What this paper addresses, then, is human ecosocial/ecological identity and consciousness. It is through the lens of ecosocial theory that we explore environmental and critical literacy in the context of this study.

\section{Review of the Literature}

In our literature review, we begin with an exploration of environment as a form of text, followed by an examination of critical literacy and its relationship to the notion of environment as text.

\section{Environment as Text}

For Stables (1996, 1998), Stables and Scott (1999), and Stables and Bishop (2001), the notion of environmental literacy implies a connection with reading and writing - with text. Thus, the environment can be considered as a form of text. Stables (1996) contended that, though many people may readily conceive of environmental literacy in terms of understanding and making sense of the environment, the idea of environment as text needs further promotion. He argued that "“environment' is, at least in part, a social construct and that textual studies offers a valid means of studying it" ( $p$. 189). His premise rests on the notion of human-environment interaction or actions determined by human values and cultural norms. These values and norms change relative to society or culture and time. In other words, they are contextually contingent. In this vein, he maintained that the environment has symbolic and moral connotations and meaning as well as a physical existence. Thus, based on the work of Saussure (1959), signs or symbols that signify meaning (semiotic) in some form constitute 'text' (Stables \& Bishop, 2001). And, in turn, texts are read. Stables (1996) stated that "we 'read' the environment as part of a complex process of generating and responding to texts. Our responses to environment form an element in the network of shared meanings which embodies society" (p. 192).

The concept of environment as text is also expressed in the writing of Golley (1998). In his introduction, Golley stated that "the landscape is a text that informs us about its capacity to produce and support life, its history, and what organisms are likely to be present" (p. ix). The possibility and notion of environment as text is implicit within other authors' works, particularly in terms of our interrelationship with nature, environment or Earth (cf. Abram, 1996; Kahn, 1999; Orr, 1992).

Stables' conception of environment as a social construct and, accordingly, as text, signifies that potential meaning is inherent within the biophysical environment (Stables \& Bishop, 2001). As well, the biophysical world is intertwined with perception of it and, consequently, the recognition that environmental issues are open to interpretation (Abram, 1996; Stables \& Bishop, 2001). This conception of environmental literacy allows for and encourages multiple perspectives or views of the environment, including the cultural and aesthetic, extending and broadening the conception of environmental thought and education beyond the dominant, Western scientific view (Stables \& Bishop, 2001). This broadened conception allows for different views of and responses to environmental issues and for alternative ways of understanding the environment. As well, 
the textual/literacy notions of reading and writing equate to 'responding to' and 'acting on' the environment. Consequently, 'taking action' is inherent within the concepts of environmental literacy and environment as text (Stables \& Bishop, 2001).

Stables and Bishop (2001) argued that this broadened conception of environmental literacy (i.e. literacy as semiotic engagement and environment as text) is not a component within environmental education, but rather subsumes environmental education, providing an overarching conceptual framework. As a conceptual framework, it shapes and reshapes human relationships with the environment.

Stables (1998, 2001) described literacy skills (i.e. print-based literacy) as functional, cultural, and critical. He relates this conceptual framework of literacy to the environment in terms of functional, cultural, and critical environmental literacy. This tripartite division is not new to discussions on the subject of literacy. For example, Norris and Phillips (2003) focused primarily on scientific literacy in its fundamental sense, that is, functional; Jenkins (1999) and Kolstø (2001) in the civic or cultural sense; and Hodson (2003) and Lemke (2002) in the critical sense. Other examples can be taken from discussions surrounding multiple literacies such as computer or media literacies. Green (1988) developed a 3D model for literacy that is essentially identical to the model employed by Stables (1998, 2001). Similarly, Scribner (1986) outlined three metaphors for a socially contextual literacy: literacy as adaptation, as power, and as a state of grace, which respectively compare to functional, critical, and cultural literacies. A tripartite focus on literacy - whether scientific, media, or environmental-helps to delineate a conception of literacy as a set of social practices involving multiple modes, carried beyond the normative view of reading and writing.

\section{Critical Literacy}

In describing critical literacy, Lankshear and Knobel (2003) stated, that "the critical dimension involves awareness that all social practices, and thus all literacies, are socially constructed and 'selective': they include some representations and classifications-values, purposes, rules, standards, and perspectives - and exclude others" (p. 11). Ecosocial theory suggests that the material world is a part of the "social practices" that "include some representations and classifications ... and exclude others" (Lankshear \& Knobel, 2003, p. 11). Freire and Macedo (1987) viewed critical literacy as the ability to read both the word and the world. Freire suggested that "reading does not consist merely of decoding the written word or language; rather it is preceded by and intertwined with knowledge of the world" (Freire \& Macedo, p. 29). By "knowledge of the world," he is not referring to only the social or human built world. For instance, in speaking of his early life as a child, Freire wrote:

The texts, words, letters of that context were incarnated in the song of the birds tanager, flycatcher, thrush - in the dance of the boughs blown by the strong winds announcing storms; in the thunder and lightening; in the rainwaters playing with geography, creating lakes, islands, rivers streams. The texts, words, letters of that context were incarnated as well in the whistle of the wind, the clouds in the sky, the sky's color, its movement; in the color of foliage, the shape of leaves, the fragrance of flowers. (p. 30) 
Freire's view of reading the world is ecosocial, including both the human and material worlds. Henry Giroux (as cited in Freire \& Macedo, 1987) noted that "central to Freire's approach to literacy is a dialectical relationship between human beings and the world, on the one hand, and language and the transformative agency, on the other" (p. 7). It is this "dialectical relationship" that allows for "the process of becoming self-critical ... and to begin to understand the political nature of the limits and possibilities that make up the larger society" (Freire \& Macedo, 1987, p. 7), and in doing so, becoming critically literate. Critical literacy brings into question hegemonic power structures that act to marginalize certain groups in favour of the dominant few (Cadiero-Kaplan, 2002). However, Bowers and Apffel-Marglin (2005) argued that Freire overlooks important aspects of "economic globalization and the ecological crisis" (p. vii). In speaking of the ecological crisis, Bowers (2005) suggested that Freire's assumptions have added to the ecological crisis by promoting, "a human-centered view of human/nature relationships, thinking of change as linear and inherently progressive in nature, representing critical inquiry and thus the autonomous individual as the only legitimate source of agency and moral authority" (p. 139). We recognize the relevance of Bower's argument. However, for the purposes of this paper, our focus is on Freire's notion of the importance of learning to read the natural world, especially as children, for developing critical literacy. Just as Freire learned as a child to read the word and the world, so too do school children today need to develop the skills necessary to become critically literate, beginning with reading their own worlds, which includes both the social and material worlds.

Learning to become critically literate begins with the development of foundational comprehension skills, such as the following skills suggested by Hassett (2008): making connections, inferring, questioning, visualizing, and synthesizing. These foundational comprehension skills that support the development of critical literacy are the focus of our findings and analysis. While critical literacy is generally considered important for older children, researchers contend that young students as well can and should develop the skills necessary for constructing critical literacy (Gregory \& Cahill, 2009; Silvers, Shorey, \& Crafton, 2010; Vasquez, 2003, 2007).

\section{Background Context of Indigenous Learners}

For decades, Canadian researchers and statisticians have documented a 'gap' in the achievement of Indigenous students compared to the average achievement of nonIndigenous peoples; the 'gap' spans from early childhood into adulthood. According to the 2004 Report from the Office of the Auditor General of Canada, there is a 28-year educational gap between on-reserve First Nations people and other Canadians. The Canadian Council On Learning's (CCL) State of Indigenous Learning in Canada 2009 explained that in British Columbia, the Early Development Index (EDI), which measures early development milestones in children, shows " $39 \%$ of Indigenous children are not ready for school" (p. 36) as compared with $25 \%$ of non-Indigenous children (p. 36). Toulouse (2008) explained that the state of Indigenous learning is clearly a crisis and turnaround and success are dependent upon real change.

The initial purpose of education for First Nations people was, as Corbiere (2000) described, primarily for assimilation. According to Cordoba (2005), education continues to use a fragmented and Euro-centric approach to teach Indigenous students. This approach is disconnected from Indigenous traditional knowledge, culture, and traditions. 
In fact, early Indigenous education was targeted to force Indigenous people to adopt Western worldviews and the English language (Barnhardt \& Kawagley, 2005), which reinforced the goals of colonization. Dion (2007) explained that while Canadian teachers are encouraged to include Indigenous content in the curriculum, they are still informed by and engaged in the dominant discourse, that of Western hegemony or Euro-centrism (2007). Thadani, Cook, Griffis, Wise, and Blakey (2010) stated that "nearly two decades ago, Haberman (1991) identified a teacher-directed, controlling, teaching style experienced by low-income and minority students. He called this style and the beliefs associated with it the "pedagogy of poverty" (p. 22). They argued that this style of teaching and its associated belief system still exists in many classrooms today.

Incorporating Indigenous Elders and artists in the school and classroom is a decolonizing practice that challenges the "hegemony of western regimes of knowledge and representation" (Dion, 2007, p. 333) and increases student self-esteem by demonstrating the value of Indigenous traditional knowledge and identity. Introducing multiple cultures in the classroom and creating a safe space to challenge the assumed Western values also enables a culturally responsive pedagogy that confronts the accepted Western hegemony (Ladson-Billings, 1995).

Epistemological shifts provided in the combination of experiential learning and the sharing of traditional ecological knowledge can achieve educational goals of increased Indigenous student self-esteem and self-efficacy, as well as recognition of their own cultural identity (Hebert, 2000). Corbiere (2000) explained that "fostering a positive self-image and forming a healthy identity are inherent in holistic education" (p. 2). Rethinking the predominant Eurocentric education perspective and integrating Indigenous perspectives is crucial to educators, Indigenous and Non-Indigenous alike, who seek to address the inherent failures and contradictions in educational pedagogy for Indigenous students (Battiste, 2005).

\section{Methodology}

Research was conducted during a year-long grade school pilot project funded through the Ontario Ministry of Educaton Teacher Leadership and Learning Program (TLLP). The TLLP program funds school-based projects which support teacher-led action research that furthers understanding of teaching and learning, predominantly in either literacy or numeracy. The research team included a university researcher, Joan, the Vice Principal of the school, Christy, and two classroom teachers who chose to participate in the project-Mary (pseudonym), the Grade 2 teacher, and Ryan (pseudonym), the Grade 6 teacher. Mary had very little prior experience in environmental education, whereas Ryan had a strong background in science and environmental education. The study school, located in a northern Canadian urban setting, was of mixed socioeconomic backgrounds with approximately $15 \%$ self-identified Indigenous students. The demographics of the individual study classrooms were:

Grade 6 Class Indigenous Population (25\%); and, Grade 2 Class Indigenous Students (22\%). 
Within the TLLP project, action research was the primary methodology; student learning and program/teaching improvement regarding critical literacy skills were the primary objectives. Kemmis and Grundy (1981) defined action-research in education as:

A family of activities in curriculum development, professional development, school improvement programmes, and systems planning and policy development. These activities have in common the identification of strategies of planned action which are implemented, and then systematically submitted to observation, reflection and change. Participants in the action being considered are integrally involved in all of these activities. (As quoted in Burns, 2000, p. 443)

In the course of the TLLP project, the teachers were the primary researchers. Joan, the university researcher, engaged in an overlying study, which followed the teachers as they conducted action research within their classrooms; Christy, the Vice Principal, worked with both the university researcher and the teachers. Together, we formed the TLLP project team.

The teachers explored and developed best practices for utilising the natural environment to teach elementary students critical literacy and thinking skills. In doing so, they effectively implemented within their own school the Ontario Ministry of Education's Acting Today, Shaping Tomorrow (2009) policy for re-introducing environmental education into Ontario Schools. The inclusion of an Indigenous Elder in the project was to help balance the Ministry's environmental policy, as it was framed in a Western science model and did not include Indigenous Knowledge within the framework. The TLLP research project sought to address this failure by re-shaping the 'box' and taking learning outside and grounding the learning in experiential settings. Critical to the TLLP was affording students the space and time to explore, inquire and synthesize their experiences in the environment through various forms including oral stories, art and written work.

Elders were incorporated in the project at critical junctures, including the planning and implementation stages of the outdoor classroom, as well as through direct work with the students. The plant selection and traditional knowledge regarding local Indigenous reliance on Indigenous flora and fauna were based on direct Elder consultation. The Elder also visited with both classes sharing traditional stories of the Anishnaabe and their reliance on the land and water in the region. Additionally, the Elder shared traditional stories of important geologic features in the surrounding region with students. Simultaneously, as part of their oral literacy learning, students were encouraged to share their own knowledge through story telling and oral sharing circles.

The teachers cooperatively planned and implemented strategies from an ecosocial perspective for developing their students' critical and environmental literacy skills, embedded in the notion of environment as text. They planned and created curriculum which engaged students on an almost daily basis with their immediate and local environment, examined questions of power and political intent and mobilized students' knowledge in multi-modal fashions (Comber, Nixon \& Reid 2007). Further, the teachers wrote reflective journals, as continual observation of implemented strategies, reflection, and planning occurred throughout the school year. 
The overlying or superimposed study, conducted by Joan, incorporated case study methodology (Yin, 2009) in order to further theoretical understanding of ecosocial theory, in particular, its fit with the notion of environment as text. The project school was the bounded case within which to examine ecosocial theory's explanatory rigor. The goal was to further develop ecosocial theory and the notion of environment as text into an integrated whole with explanatory and practical relevance.

Data for both the TLLP action research project and the overlying case study were collected from varied sources: researcher field notes and reflections; teacher conversations and reflections; student observations, projects/products, and conversations conducted by the teacher-researchers; video and photographic images of and by students and teachers as they engaged with the environment; qualitative measurements of students' critical and environmental literacy skills through administered assessment instruments (that is, environmental knowledge and attitude surveys for Grades 2 and 6 both pre and post intervention); and other possible indicators of student learning. Hermeneutic methods for qualitative data analysis was used based on both a priori and emergent themes (cf. Smith, 2010). The research project and data analysis were supported through the use of Atlas.ti, Qualitative Data Analysis Software (QDAS) capable of handling a large amount of rich textual and image data.

The teachers focused their efforts on supporting students in developing foundational comprehension skills that support critical literacy development. The skills focused on in the study included making connections (the overarching skill), questioning, inferring, visualizing, and synthesizing. Similar to Hassett's (2008) approach, the teachers allowed space for the children to "play with...language and ideas...[which] is the same thing as playing with comprehension strategies: questioning, visualizing, inferring, connecting with ideas, expanding ideas, making educated guesses, imagining" (p. 314) through the context of the environment as the teaching text. Further, as suggested by Hall (2003), the teachers created classrooms centred on critical literacy where "teachers and pupils work together to see how texts construct their worlds, cultures and communities" (as quoted in Fisher, 2008, p. 20). Taking a broad view of what constitutes 'text', the children and their teachers brought the environment into their construction of their "worlds, cultures, and communities."

In addition to the interest in critical literacy skill development, the TLLP project team was keenly interested in how the project might benefit Indigenous students. The kinesthetic, land-based lesson and unit design, coupled with the project's outdoor classroom or school garden were also recognized for their role in positively impacting student academic achievement (Williams \& Dixon, 2013), particularly with respect to Indigenous learners in the classroom. The inclusion of Elder teachings as well as Indigenous traditional ecological knowledge in the project and outdoor classroom design embraced Indigenous cultural learning styles and approaches (Battiste, 2005) and impacted not only achievement, but student and parent engagement as well (Toulouse, 2008). Inclusion of Indigenous world-views and Elders' knowledge was crucial to the project as a means of addressing the achievement gap between Indigenous and nonIndigenous learners. 


\section{Findings}

Throughout the school year, the children in both the Grade 2 and Grade 6 study classrooms were given multiple opportunities to engage with the environment as the context for teaching and learning. Though data were gathered from both Grades, this paper focuses primarily on the data from Mary's Grade 2 classroom.

Although the lessons were not necessarily specifically focused on language and literacy (science, mathematics, and art among other subject areas were also part of the outdoor/indoor curriculum), language and literacy skills were a part of every lesson and experiential activity. For example, the teachers listened to the children as they developed oral literacy skills through their excited discussions around what they observed, and what they inferred from their observations and discoveries. Mary, the Grade 2 teacher shared these thoughts:

When in the natural environment there are so many different ways of learning that you can get to everybody. Some kids that don't normally orally share in the classroom, if they're outside and talking and orally sharing can't I assess that? Isn't that oral sharing too? ... There are so many rich assessments just by listening to kids.

The teachers approached teaching and learning as interconnected and "advocate[d] an attitude of mindful participation" (Davis, 2004, p. 176). What occurred outside the classroom was brought into the classroom and vice versa-a weaving of language, literacy, place, community, school, learning, and ecosocial well being. Consequently, it seems somewhat artificial to discuss separately the various critical literacy or comprehension skills the children were developing as they were interwoven within a broader view of learning; however, for the sake of simplicity and clarity, the following discussion of findings will examine each of the previously identified target critical literacy skills of making connections, inferring, questioning, visualizing, and synthesizing. We then discuss some significant additional findings regarding literacy and learners in general.

\section{Critical Literacy}

Though we acknowledge that "comprehension is never enough: it must have a critical edge" (Pearson, D. in Literacy GAINS, 2009, p. 1), in the following discussion of our findings concerning critical literacy, we have chosen to separate the discussion into the categories related to the various foundational comprehension skills previously identified as essential for developing critical literacy. We begin with making connections, the central skill necessary for the development of the other skills foundational to critical literacy.

Making connections. "Readers relate what they read to personal experiences (textto-self), to information from other text (text-to-text), and to information about the world (text-to-world) in order to enhance understanding of self, text, and life" [Wisconsin Educational Communications Board (WECB), 2006 - 2013]. Making connections is the overarching comprehension skill as this skill is required in order to be able to visualize, 
infer, synthesize, and question, especially at a deeper level. It is taking children to a deeper level of comprehension and thinking that allows for critical literacy.

In the following example, the children in Grade 2 demonstrated making connections when they brought the natural world into their classroom with a worm farm. One Grade 2 student expressed excitement by saying, "Worms are so cool! Worms help gardens grow!" Their teacher was amazed by their responses to the worms:

Even the worm farm, which is the simplest little thing - I could not believe the connections! Even now they come up to me and ask about worms. In their writing they talk about worms. (Mary, focus group interview)

The worms were real and concrete, and relevant to the children as they found worms all around them in the natural environment and in the school garden, as well as their classroom. But making connections with text (in whatever form that might present itself) is not always so straightforward or easy as Christy, the Vice Principal, attested:

We spend an inordinate amount of time trying to teach kids how to make connections to things. ... Every year we put it in our school plan and it's in our board plan - making connections, making connections ... We're just beating a dead horse right now and can't figure out why and I think it's because we're not helping them make any relevant connections. We're giving them a book by van Allsburg about The Sweetest Fig but if you've never seen a fig tree or don't know how they grow or understand what's special about figs, you just can't go there. (Christy, focus group interview)

There were numerous examples in the data gathered from the children in both Grades 2 and 6 that make inter-connections with the 'text' found in the natural world around them, which "enhance[s] understanding of self, text, and life" (WECB).

Inferring. According to the WECB (2006 - 2013) literacy education website Into the Book, inferring occurs when "readers think about and search the text, and sometimes use personal knowledge to construct meaning beyond what is literally stated." In a similar vein, the students in the study classrooms were asked to make inferences based on prior knowledge and their observations of their surroundings to "construct meaning beyond" just what their senses told them; beyond what they saw, felt, or heard. In analyzing the data, many instances and examples of the children making inferences occurred both in and outside the classroom. The following excerpt from the Grade 2 teacher's reflective notes provides an example:

"We found a footprint!" "Maybe it's from a fox." "No, it's probably from a dog because lots of people walk their dogs here." As they formulated and reformulated their ideas they were sharing their background knowledge, making inferences and extending their knowledge. (Mary, reflective notes) 
The children in this example were able to 'read' the environmental semiotic signs to make inferences and meaning out of what they read and to make connections to their world.

Questioning. According to Hassett (2008), "generating questions before, during, and after reading are necessary skills for deep comprehension" (p. 313). We suggest that the notion of questioning also applies to reading the world and being able to comprehend it. During a focus group interview, Christy commented,

When you gave [children] this opportunity [to be outside], we opened that natural path so when you did come back and ask them to do some more traditional tasks, they had the inspiration, they had the questions flowing; their need to find answers, their need to talk about it ... and write about it, was opened up. We didn't have to force it; we didn't have to facilitate it. That relevance of what we're doing in order to get all children on board talking and thinking about their world and connections to it.

The children's critical literacy skill development in asking questions was enhanced through their experiences in the natural world. Further examples of the power and role the out-of-doors played in helping the children develop questioning skills are provided by the Grade 2 teacher, Mary:

As they began to look up at the sky, I heard someone say, "Look the clouds are moving really fast!" then another say, "It's windy so the wind must be moving them." Then another say, "I wonder if they move faster or slower when it's cold?" You could sense the excitement in their questions and that they wanted to find the answers to their questions. (Mary, reflective notes)

And,

Couple of times I would just go in the schoolyard and say, "let's just look around." ... You don't have to tell them every single thing ... you just let them go and they're going to ask a million questions and come and show you and figure things out on their own. (Mary, focus group interview)

Visualizing. As defined by the WECB (2006-2013), visualizing occurs when "readers create images in their minds that reflect or represent the ideas in the text. These images may include any of the five senses and serve to enhance understanding of the text." The children were given numerous opportunities for using their senses when interacting with the environment as text. These rich interactions provided the children with relevant and contextual imagery for their in-class writing and drawing (Figure 2).

When we went fishing, I liked that we got to touch all kinds of water bugs! ... The backswimmer was cool because it can defend itself because the top the birds can't see and the bottom the fish can't see! (Grade 2 student) 


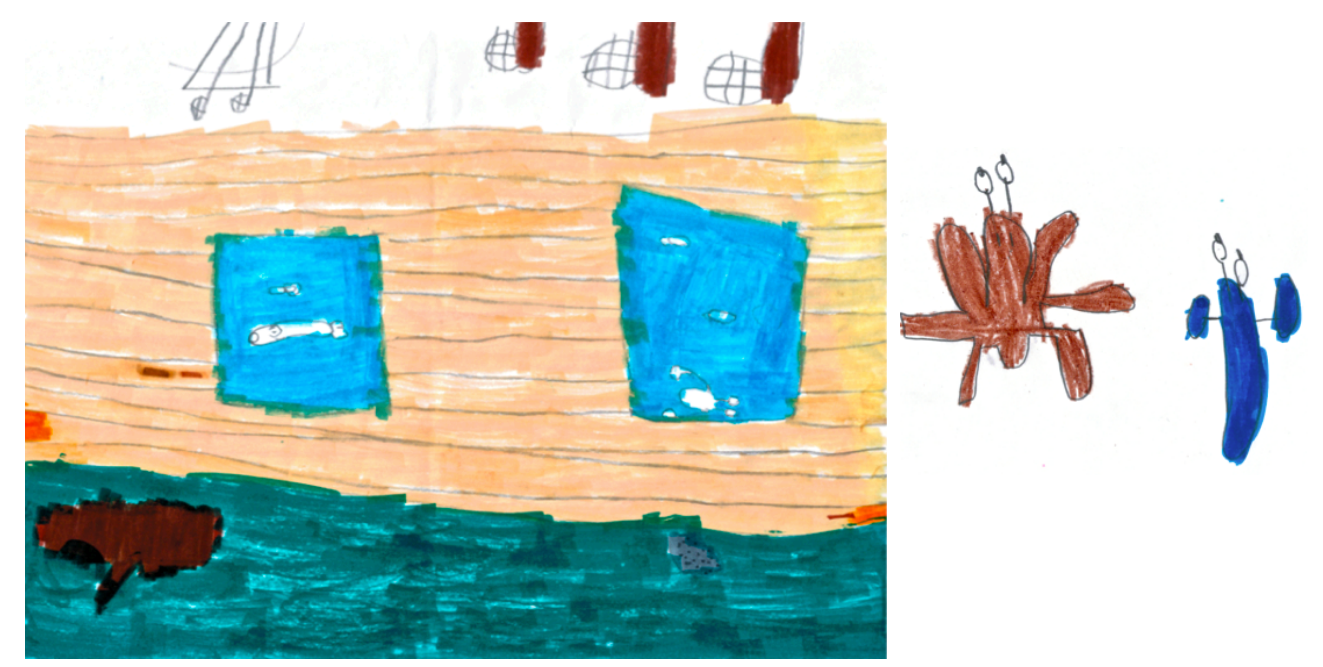

Figure 2. Grade 2 student's drawing (visualization) of a backswimmer and other aquatic wildlife.

And as the year progressed and the children's ability to 'read' the environment improved, they were able to visualize more accurately and reflect on what it was they were seeing and noticing.

[At the beginning of the year] ... talking about tracks in the snow ... the different animals they were listing was Pegasus and Yoshi; they didn't have a concept of what animals are in the forest. Now to see those same kids that had no concept of wildlife ... we went on a leaf walk and we saw tracks and "Oh, that's a deer." (Erin, research assistant commenting on her observations of Grade 2 students focus group interview)

The children were able to observe the tracks and recognize the animal that had likely made them. Adding to this, the Grade 2 teacher, Mary, commented on the importance of the children being able to use their senses for learning and understanding, for visualizing:

Throughout this project, providing students with access to the natural world has allowed me to observe the rich learning that happens when children are immersed in their environment. They are not watching it on a television screen, they are not engaged in simulation on a computer, they are not learning about it as a book is read to them, rather they are sensing, touching, smelling, and feeling the natural world first hand. (Mary, reflective notes)

Through their immersion in the world around them, the children were able to richly visualize and express these sensory experiences in traditional literacy-based formats upon their return to the classroom.

Synthesizing. As the Vice Principal remarked, the TLLP project "opened a ton of pathways for natural inquiry. Good accountable talk in our classrooms, rich discussions; 
things to move kids forward on thinking levels," (Christy, focus group interview) which provided many opportunities for "readers to create original insights, perspectives and understandings by reflecting on text(s) and merging elements from text and existing schema" (WECB, 2006 - 2013) and, consequently, synthesis to occur. For example, a Grade 2 student's thoughts about a nearby housing development:

I see it every day because I am so close to it! The construction is good because my friends are going to move in there. It used to be a beautiful place but they destroyed nature to make houses. Nature helps animals live and it keeps us healthy. (Grade 2 student)

Or the Grade 2 teacher's reflection about her students:

As they inquired, they tried to help each other to solve the problems and questions posed by adding in their ideas, listening to their peers, responding and reformulating their ideas. ... [For example], we learned that you can tell a lot about an animal's movement by examining their tracks. By making their own tracks the students were able to put themselves in the animals' 'shoes' and think from the perspective of an animal. (Mary, reflective notes)

The synthesizing skills the children developed in "merging elements from [the environment as text] and existing schema" (WECB) allowed for the far transference of these skills to literacy-based texts in the classroom setting.

\section{Additional Findings}

Though the primary goal of the TLLP project was to improve student critical literacy skills, we were encouraged by the depth of skill and transference the students presented. For example, some of the Grade 2 children were able to identify, without prompting, both sides of a local issue (housing development) and provide arguments to support both, in writing and imagery. As one Grade 2 student wrote when asked their thoughts on the new housing development adjacent to the school:

It is good because they are making homes for humans, but I don't think it's very nice and nature needs to live and they are kind of tearing down the trees and stuff, and there's some animals in there and they are losing their homes.

Her response, as well as others by fellow students, is significant because the concept of identifying two sides of an argument and presenting both points of view is a skill that the Ontario language curriculum does not emphasize until Grade 6.

Additionally, the students acquired skills that could not directly be characterized as critical literacy skills, but which nonetheless supported the children as learners as they engaged in the daily work of school and literacy building. An example is independence and self-efficacy, as described by the Vice Principal, Christy:

Building autonomous learners who have inquiry skills and problem solving skills - and what we saw was autonomy was increasing; kids feel good about 
themselves, they are taking more risks in what they're doing in the classroom and outside the classroom. ... Ryan did many activities on how we actually observe the world a little more formalized beyond just asking what we see. ...There were visualizing pieces and then the problem solving skills ... lots of opportunities to do those things that really build those autonomous learners. Because beyond the academic piece ... there is this whole social and emotional well-being piece ... that is a huge barrier to kids being able to do anything else. If you don't have any feeling of 'I can do this' or you don't have any kind of risk taking behaviours or ability to think about a problem ... reading and writing is just extra. (Christy, focus group interview)

The children also learned skills such as listening that supported their overall learning. For instance, Mary noted that "when watching birds land on a bird feeder ... the children could watch how the birds interacted, learn the importance of respect for nature, the importance of listening and quietness and how that helped their learning".

Utilizing the learned critical literacy skills, the children expanded their knowledge and investigated the needs of endangered species or energy saving actions, among other inquiries. For example, the Grade 2 children celebrated a Puffin Day where they dressed as puffins and demonstrated their understanding of the needs of puffins uncovered through the children's inquiry. An excerpt from a Grade 2 graphic novella provides an example: "Our class adopted a puffin! Taking ownership of nature helps us to be more responsible citizens. We learned all about puffins and how we are helping protect nature". The Grade 6 children wrote about Earth Hour and its importance in demonstrating that each of us can contribute to environmental practices, which will impact Earth. They then participated in Earth Hour and considered further their daily practices for saving energy at home and at school.

\section{Discussion}

The TLLP project's teachers enthusiastically reported the project to be a resounding success. In the focus group interview, both teachers expressed that their teaching practice has been irrevocably changed-they were amazed at the benefits and gains, not only in literacy achievement and academic improvement in other subject areas, but also in the social development and growth of the whole child, particularly in terms of respect for self, others, and the environment. The curriculum the children experienced, with the environment as the integrating text, seemed relevant and deeply meaningful because, by appearances, they concretely experienced the lived world around them. As argued by Vasquez (2003), "a critical literacy curriculum needs to be lived. It arises from the [eco]social and political conditions that unfold in communities in which we live. As such it cannot be traditionally taught" (p. 12).

Through utilizing the environment as the teaching text, the children made significant gains in their ability to make connections when inferring, questioning, visualizing and synthesizing, particularly those children considered to be at risk or marginalized learners such as Indigenous children. According to the teachers and the Vice Principal, the children were better able to make those relevant and meaningful personal connections between the world and the classroom, developed the prerequisite skills, and were better able to transfer this knowledge into their literacy growth. As Freire 
(1998) asserted, "they knew how to ask and answer important questions,... and to read beyond the word, picture, gesture, or symbol, as they read the world" (in Silvers, Shorey, $\&$ Crafton, 2010, p. 402). The world the students read was their own local world, a place to which they could connect and make meaning. As Mary stated, "We as teachers know that a [place-based] hands-on approach would be richer and provide students with that connection that they need in order to make sense of their world, question their world and create meaning" (Mary, reflective notes).

The significance of place should not go unnoticed as it made a substantial difference particularly for the classes' Indigenous students. The children were engaged in their learning and willing to come to school, as evidenced by fewer absences than in preceding years. Additionally, parents of the Indigenous children commented to the teachers that for the first time, their children felt like they fit, that they belonged (Mary \& Ryan, focus group interview). As Hare (2012) noted, "(F)or indigenous children, the need to bridge indigenous family and community cultural and linguistic experiences with school based literacy expectations and practices is critical to improving their educational outcomes and future success and well-being" (p. 391). The project's activities and teaching practices helped create those necessary bridges.

In learning the foundational skills for critical literacy, the children were able to question and take action in order to make a difference (however small) in their worldinquiry and participation in Earth Hour (Grade 6) and adopting a puffin (Grade 2) were two such examples. The activities and outings the teachers thoughtfully orchestrated, reflected the children's interests, needs and place in their world, deepening student engagement and learning.

In the context of this project, ecosocial theory helps explain the interconnection of the children and their social and ecological worlds. The theory suggests that language and identity are dynamically formed as part of both social and material or physical semiotic resource systems and processes. Viewing the environment as a form of text allows for the practical interweaving of these systems and processes in an educational context.

\section{Pathways for Future Research and Conclusion}

Challenges arose throughout the research period, some of which were successfully addressed and others remain as opportunities for future research. Because team members brought a range of teaching, organizational, and communication skills, as well as widely varied level of ecological education schema, building a cohesive professional learning team was challenging. Team members represented three educational divisions - primary, junior, and intermediate-within the school and this presented a challenge to create activities that accounted for varied student abilities as well. Leadership, clear communication, and a single focused vision on the outcome were critical in overcoming this obstacle. Team members also had to think creatively, often outside their comfort zones, and share openly, both successes and challenges, with each other in order to create a cohesive final outcome.

Questions for future research include:

- Will the school culture continue to build upon this starting point and use the natural environment as a teaching tool? 
- How might outdoor classrooms inclusive of traditional ecological knowledge be engaged in closing gaps in achievement for Indigenous learners?

- How might the natural environment be engaged to teach " $21^{\text {st }}$ Century learning skills"?

- How might developing ecological education capacity within a few staff leaders engage and transform a whole school culture?

- How might extended experiential learning in the natural environment affect literacy achievement within a school, board and region?

Though only one small project at one school, the findings from this study demonstrate the possibilities that using the environment as a teaching text offers for literacy gains of all children, but in particular for Indigenous learners. Further research in this area is needed to corroborate our findings and extend the beginning understandings of the processes involved in literacy learning and engagement when children are taken out of the classroom and allowed to interact with the world around them.

\section{Acknowledgements}

The authors wish to acknowledge the Ontario Ministry of Education for their funding support for the Teacher Leadership and Learning Program project and the Faculty of Education at Lakehead University for their support in making this research possible. We also wish to thank Dr. Gerald Walton (Lakehead University), and anonymous reviewers for their efforts, encouragement, and helpful suggestions.

\section{References}

Abram, D. (1996). The spell of the sensuous: Perception and language in a more-thanhuman world. New York: Pantheon Books.

Barnhardt, R., \& Kawagley, A.O. (2005). Indigenous knowledge systems and Alaska Native ways of knowing. Anthropology and Education Quarterly, 36(1), 8-23. doi: 10.1525/aeq.2005.36.1.008

Battiste, M. (2005). Indigenous knowledge: Foundations for First Nations. Retrieved from http://www.winhec.org/winhec/docs/pdfs/Journal/Marie\%20Battiste\%20copy.pdf

Bowers, C. A. (2005). How the ideas of Paulo Freire contribute to the cultural roots of the ecological crisis. In C. A. Bowers \& F. Apffel-Marglin (Eds.), Rethinking Freire: Globalization and the environmental crisis (pp. 133-150). Mahwah, NJ: Lawrence Erlbaum Associates.

Bowers, C. A., \& Apffel-Marglin, F. (Eds.) (2005). Rethinking Freire: Globalization and the environmental crisis. Mahwah, NJ: Lawrence Erlbaum Associates.

Burns, R. B. (2000). Introduction to research methods. London: Sage Publications.

Cadiero-Kaplan, K. (2002). Literacy ideologies: Critically engaging the language arts curriculum. Language Arts, 79(5), 372-381. Retrieved from http://www.ncte.org/library/NCTEFiles/Resources/Journals/LA/0795may02/LA0795Literacy.pdf 
Canadian Council on Learning. (2009). The state of Indigenous learning in Canada: A holistic approach to measuring success. Ottawa. Retrieved from www.cclcca.ca/sal2009.

Comber, B., Nixon, H., \& Reid, J. (Eds.) (2007). Literacies in place: Teaching environmental communications. Newtown, NSW. Primary English Teaching Association Australia.

Corbiere, A. O. (2000). Reconciling epistemological orientations: Toward a wholistic nishnaabe (Ojibwe/Odawa/Potawatomi) education. Paper presented at the Annual Meeting of the Canadian and Indigenous and Native Studies Association (CINSA), May 28-31, 2000, Edmonton, AB.

Cordoba, T. (2005). Indigenous literacy and education: A wholistic perspective that embraces intergenerational knowledge. Paper presented at $9^{\text {th }}$ Provincial Indigenous Education Conference, Nov 1-3, Whistler, B.C.

Davis, B. (2004). Inventions of teaching: A genealogy. Mahwah, NJ: Lawrence Earlbaum Associates.

Dion, S. D. (2007). Disrupting molded images: Identities, responsibilities and relationships-teachers and Indigenous subject material. Teaching Education, 18(4), 329-342. doi: 10.1080/10476210701687625

Fisher, A. (2008). Teaching comprehension and critical literacy: Investigating guided reading in three primary classrooms. Literacy, 42(1), 19-28. doi: 10.1111/j.14679345.2008.00477.x

Freire, P., \& Macedo, D. (1987). Literacy: Reading the word \& the world. South Hadley, MA: Bergin \& Garvey Publishers.

Fullan, M. (2013). Great to excellent: Launching the next stage of Ontario's education agenda. Retrieved from http://www.edu.gov.on.ca/eng/document/reports/fullan.html.

Golley, F. B. (1998). A primer for environmental literacy. New Haven, CT: Yale University Press.

Green, B. (1988). Subject-specific literacy and school learning: A focus on writing. Australian Journal of Education, 32(2), 156-179. doi: 10.1177/000494418803200203

Gregory, A. E., \& Cahill, M. A. (2009). Constructing critical literacy: Self-reflexive ways for curriculum and pedagogy. Critical Literacy: Theories and Practices, 3(2), 616.

Hall, K. (2003). Listening to Stephen read: Multiple perspectives on literacy. Buckingham: Open University Press.

Hare, J. (2012). 'They tell a story and there's meaning behind that story': Indigenous knowledge and young Indigenous children's literacy learning. Journal of Early Childhood Literacy, 12(4), 389-414. doi: 10.1177/1468798411417378

Hassett, D. (2008). Teacher flexibility and judgment: A multidynamic literacy theory. Journal of Early Childhood Literacy, 8(3) 295-327. doi: $10.1177 / 1468798408096479$

Hodson, D. (2003). Time for action: Science education for an alternative future. International Journal of Science Education, 25(6), 645-670. doi: 10.1080/09500690305021 
Jenkins, E. W. (1999). School science, citizenship and the public understanding of science. International Journal of Science Education, 21(7), 703-710. doi: 10.1080/095006999290363

Kahn, P. H., Jr. (1999). The human relationship with nature: Development and culture. Cambridge, MA: The MIT Press.

KolstØ, S. D. (2001). Scientific literacy for citizenship: Tools for dealing with the science dimension of controversial socioscientific issues. Science Education, 85(3), 291-310. doi: 10.1002/sce.1011

Ladson-Billings, G. (1995). Toward a theory of culturally responsive pedagogy. American Educational Research Journal. 32(3), 465-491. Retrieved from http://www.jstor.org/stable/1163320

Lankshear, C., \& Knobel, M. (2003). New literacies: Changing knowledge and classroom learning. Philadelphia, PA: Open University Press.

Lemke, J. L. (1995). Textual politics: Discourse and social dynamics. London: Taylor \& Francis.

Lemke, J. L. (2002). Getting critical about science literacies. Paper presented at the Language and Science Literacy Conference, University of Victoria, B.C.

Literacy GAINS (2009). Connecting practice and research: Critical literacy guide. Retrieved from http://www.edugains.ca/resourcesLIT/CoreResources/Critical_Literacy_Guide.pd f

Luke, A., \& Freebody, P. (1997). Critical literacy and the question of normativity: An introduction. In S. Muspratt, A. Luke, \& P. Freebody (Eds.), Constructing critical literacies: Teaching and learning textual practice (pp. 1-18). Cresskill, NJ: Hampton Press.

Merleau-Ponty, M. (1962). Phenomenology of perception. London: Routledge and Kegan Paul.

Norris, S. P., \& Phillips, L. M. (2003). How literacy in its fundamental sense is central to scientific literacy. Science Education, 87(2), 224-240. doi: 10.1002/sce.10066

Ontario Ministry of Education (2009). Acting Today, Shaping Tomorrow. Retrieved from http://www.edu.gov.on.ca/eng/teachers/enviroed/action.html

Orr, D. W. (1992). Ecological literacy: Education and the transition to a postmodern world. Albany: State University of New York Press.

Richards, J., Hove, J., \& Afolabi, K. (2008). A CD Howe Institute commentary: Understanding the Indigenous / Non-Indigenous gap in student performance: Lessons from British Columbia. Retrieved from http://www.cdhowe.org/pdf/commentary_276.pdf

Saussure, F. de (1959). Course in general linguistics (W. Baskin, Trans.). New York: Philosophy Library.

Scribner, S. (1986). Literacy in three metaphors. In N. Stein (Ed.), Literacy in American Schools: Learning to read and write. Chicago: University of Chicago Press.

Silvers, P., Shorey, M., \& Crafton, L. (2010). Critical literacy in a primary multiliteracies classroom: The Hurricane Group. Journal of Early Childhood Literacy, 10(4) 379-409. doi: 10.1177/1468798410382354 
Smith, D. G. (2010). Hermeneutic inquiry in C. Kridel (Ed.) Encyclopedia of curriculum studies, pp. 433-437. Thousand Oaks, CA: Sage Publications. doi:

10.4135/9781412958806.n233

Stables, A. (1996). Reading the environment as text: Literary theory and environmental education. Environmental Education Research, 2(2), 189-195. doi: 10.1080/1350462960020205

Stables, A. (1998). Environmental literacy: Functional, cultural, critical. The case of the SCAA guidelines. Environmental Education Research, 4(2), 155-164. doi: $10.1080 / 1350462980040203$

Stables, A. (2001). Who drew the sky? Conflicting assumptions in environmental education. Educational Philosophy and Theory, 33(2), 245-256. doi: 10.1111/j.1469-5812.2001.tb00266.x

Stables, A., \& Bishop, K. (2001). Weak and strong conceptions of environmental literacy: Implications for environmental education. Environmental Education Research, 7(1), 89-97. doi: 10.1080/13504620125643

Stables, A., \& Scott, W. (1999). Environmental education and the discourses of humanist modernity: Redefining critical environmental literacy. Educational Philosophy and Theory, 31(2), 145-155. doi: 10.1111/j.1469-5812.1999.tb00381.x

Stables, A., \& Scott, W. (2002). The quest for holism in education for sustainable development. Environmental Education Research, 8(1), 53-60. doi: $10.1080 / 13504620120109655$

Thadani, V., Cook, M., Griffis, K., Wise. J., \& Blakey, A. (2010). The possibilities and limitations of curriculum-based science inquiry interventions for challenging the "pedagogy of poverty". Equity \& Excellence In Education, 43(1), 21-37. doi: $10.1080 / 10665680903408908$

Toulouse, P. R. (2008). Integrating Aboriginal teaching and values into the classroom. Monographs of The Literacy and Numeracy Secretariat What Works? Research into Practice. (Research Monograph \#11). Retrieved from http:/www.edu.gov.on.ca/eng/literacynumeracy/inspire/research/Toulouse.pdf

Vasquez, V. (2003). Negotiating critical literacies with young children. Mahwah, NJ: Lawrence Erlbaum Association.

Vasquez, V. (2007). Using the everyday to engage in critical literacy with young children. New England Reading Association Journal, 43, 6-11.

Vygotsky, L. (1934/1986). Thought and language (A. Kozulin, Trans. Rev. ed.). Cambridge, MA: MIT Press.

Williams, D. R., \& Dixon, P. S. (2013). Impact of garden-based learning on academic outcomes in schools: Synthesis of research between 1990 and 2010. Review of Educational Research, 83(2), 211-235. doi: 10.3102/0034654313475824

Wisconsin Educational Communications Board (WECB). (2006-2013). Into the book. Retrieved from http://reading.ecb.org/teacher/strategies.html

Yin, R. K. (2009). Case study research: Design and methods. (4 ${ }^{\text {th }}$ ed.) Los Angeles, LA: Sage. 


\section{Author Biographies}

Dr. Joan M. Chambers is an Associate Professor in the Faculty of Education at Lakehead University in Thunder Bay, ON, Canada. Her research interests include language and discourse, environmental and ecojustice education, ecosocial theory, and science teaching and learning for young children.

Christy L. Radbourne, M.Ed., is now a Principal with Lakehead District School Board in Thunder Bay, Ontario, Canada. She has been an administrator and elementary teacher with the Lakehead District School Board for 14 years. She is currently enrolled in the Joint PhD program at Lakehead University, Brock University and the University of Windsor. Her Masters work focused on culturally relevant teaching practices and pedagogy for Aboriginal Students and her research interests include environmental education, educational leadership, Aboriginal education and socio-ecological justice. 